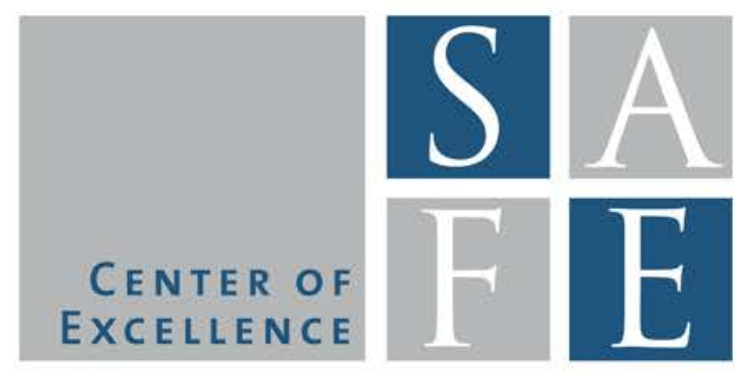

WORKING PAPER SERIES

Markku Kaustia - Antti Lehtoranta - Vesa Puttonen

\title{
Does sophistication affect long-term return expectations? Evidence from financial advisers' exam scores
}

SAFE Working Paper Series No. 3

Center of Excellence SAFE Sustainable Architecture for Finance in Europe A cooperation of the Center for Financial Studies and Goethe University Frankfurt 


\title{
Does sophistication affect long-term return expectations? Evidence from financial advisers' exam scores
}

\author{
Markku Kaustia $^{\mathrm{a}}$, Antti Lehtoranta ${ }^{\mathrm{a}}$, Vesa Puttonen ${ }^{\mathrm{a}}$ \\ ${ }^{a}$ Aalto University, P.O. Box 21220, FI-00076 AALTO, Finland
}

\begin{abstract}
We use unique data from financial advisers' professional exam scores and combine it with other variables to create an index of financial sophistication. Using this index to explain long-term stock return expectations, we find that more sophisticated financial advisers tend to have lower return expectations. A one standard deviation increase in the sophistication index reduces expected returns by 1.1 percentage points. The effect is stronger for emerging market stocks (2.3 percentage points). The sophistication effect contributes $60 \%$ to the model fit, while employer fixed effects combined contribute less than $30 \%$. These results help understand the formation of potentially excessively optimistic expectations.
\end{abstract}

Keywords: stock return expectations, sophistication, financial literacy, adviser

JEL codes: D84, G11, G24

\footnotetext{
Email addresses: markku.kaustia@aalto.fi, antti.lehtoranta@aalto.fi and vesa.puttonen@aalto.fi. We thank Marianne Bertrand, Sevinc Cukurova, Aswath Damodaran, Markus Glaser, Michael Haliassos, Arvid Hoffman, Ron Kaniel, Matti Keloharju, Karolin Kirschenmann, Samuli Knüpfer, Minna Martikainen, Allen Rappaport, Paolo Sodini, Denis Sosyura, Andrew F. Thompson Jr., Sami Torstila, Annette Vissing-Jørgensen, Midwest Finance Association Conference 2011 participants, Aalto Finance brown-bag seminar participants, and Graduate School of Finance Summer Workshop participants for comments. We are grateful for Pasi Poikkeus (Mandatum Private Bank) and Antti Lehtinen for help in developing the questionnaire, and Tatu Seppä and Marita Grönvall-Jansson for help with the data. We acknowledge financial support from the Nasdaq OMX Foundation and OP-Pohjola Group Reseach Foundation. Parts of this work were completed while Kaustia was visiting at Ross School of Business, University of Michigan.
} 


\section{Introduction}

Shiller (1984, 1990) and Vissing-Jørgensen (2003) contend that identifying the determinants of potentially excessively optimistic expectations can increase our understanding of asset pricing bubbles. In this paper we examine the link between stock market return expectations and financial sophistication. Accounts of speculative episodes suggest that particularly the less sophisticated investors are susceptible to excessive optimism. ${ }^{1}$ Consequently, financial sophistication and return expectations could be negatively related. Lack of sophistication has been shown to be linked to investment mistakes in general Calvet, Campbell, and Sodini. 2009). ${ }^{2}$ Whether sophistication affects return expectations is ultimately an empirical question. For example, even if the less sophisticated are more prone to over optimism, they might rationally anticipate this and rely less on their own views, giving more weight to the long-term historical mean return.

We use data from financial advisors to identify the relation between expectations and financial sophistication. The nature of this subject pool has several implications. It imposes a requirement of at least some level of financial sophistication on the subjects. This makes our tests more conservative to the extent that the effects would be larger among less sophisticated investors. Professionals could also suffer from behavioral bias, though likely to a lesser degree

\footnotetext{
${ }^{1}$ For example, a Paine-Webber/Gallup survey at the height of the tech stock bubble in 1999 shows that investors with less than five years of experience expected 10-year returns of $22.6 \%$, while those with 20 or more years of experience expected a more modest $12.9 \%$ (Fortune Magazine, November 22, 1999, "Mr. Buffett on the Stock Market")

${ }^{2}$ See also Feng and Seasholes (2005), Agnew (2006), Dhar and Zhu 2006), Goetzmann and Kumar (2008), Rantapuska and Knüpfer (2008), Kumar (2009b), Christelis, Jappelli, and Padula (2010), Seru, Shumway, and Stoffman (2010), Grinblatt, Keloharju, and Linnainmaa (2011), Cronqvist and Siegel (2012) and Grinblatt et al. (2012).
} 
than laymen (List, 2003). ${ }^{3}$ Unlike in surveys of laymen, such as UBS/Gallup investor surveys or the Health and Retirement Study (HRS), we are asking the subjects about their expectations regarding a quantity that is central in their work. The subjects thus have context specific experience, helping with the generalizability of any findings (see Harrison and List, 2004, for discussion).

We obtain data on the financial advisers' test scores in a professional exam in Finland. The exams cover basics of finance, economics, accounting, and law. We link these data to a survey of advisers' stock return expectations conducted in $2006 .{ }^{4}$ The response rate on the return expectations survey is $68 \%$, alleviating concerns of a nonresponse bias, and also in stark contrast to most survey studies in finance with $5 \%$ to $10 \%$ response rates. ${ }^{5}$ Of the 742 advisers for whom we have the survey data we are able to match 692 individuals to data on exam performance.

We create a sophistication index with principal factor analysis ${ }^{6}$ using the test scores, general educational attainment, an indicator for passing a more advanced second level exam, and gender. The resulting composite index is positively associated with self-perceived ability to form rational return forecasts, as well with using information sources in a predicted manner.

${ }^{3}$ Financial advisers' return expectations have anchoring bias, but to a smaller degree than student subjects Kaustia, Alho, and Puttonen 2008. Sometimes professionals can be more biased: Haigh and List 2005) find that CBOT traders are more myopically loss averse than a control group of students.

4 Stock market development had been rather favorable in years prior to collecting the data on expectations. Later we discuss additional data involving expectations measured in 2009-2012, largely a bear market period.

${ }^{5}$ For example, the response rate in the CFO surveys of Graham and Harvey (2012) is 5\% to 8\%.

6 There is a subtle difference between principal factor analysis and principal component analysis, where principal factor analysis is more closely in line with our underlying assumptions. For robustness, we estimate everything also using principal component analysis, which leads to virtually identical results. 
Of the index components, gender is the least justified ex ante. However, we include it based on prior research showing that the male gender is strongly associated with better financial literacy among the general population after controlling for other factors (Chen and Volpe, 2002; Lusardi and Mitchell, 2008, van Rooij, Lusardi, and Alessie, 2011). It is nevertheless unclear ex ante whether this gender effect would extend to professional financial advisers. We therefore estimate all our results also with an alternative version of the sophistication index that does not include gender. This produces results that are qualitatively similar but slightly weaker.

We find that more sophisticated advisers do have lower stock return expectations and the effect is highly statistically significant. A one standard deviation increase in the sophistication index corresponds to a 1.1 percentage point reduction in the expected annualized 20-year return on the European stock market. The effect is larger for emerging market stocks: a one standard deviation increase corresponds to a 2.3 percentage point decrease in return expectations. Given recent estimates of the equity premium around 3-4\% Claus and Thomas. 2001; Fama and French, 2002; Donaldson, Kamstra, and Kramer, 2010), these effects seem rather large economically.

High return expectations do not necessarily constitute a mistake. A single individual could well expect, for example, long-term annual returns of $15 \%$ for fully rational reasons. Several factors nevertheless make us suspect that a behavioral bias of over optimism is at least partially behind the effect we document. First, we find that less informed agents do not just have more diffuse expectations, but tend to have systematically higher expectations. Over optimism, rather than over pessimism, has generally been found to be the more prevalent pattern of deviating from an unbiased forecast (see, e.g., Weinstein, 1980, Hoch, 1984, Puri and Robinson, 
2007). Second, as mentioned, previous studies find a robust association between lack of sophistication and investment mistakes in other domains. One could extrapolate that also with return expectations, the relatively less sophisticated agents are more biased, rather than less biased. Third, we find a false consensus effect, namely that advisers on average expect other advisors to have higher expectations. Thus the advisers do not try to outbid the consensus - in fact, they are undercutting it. This suggests that advisers themselves think that lower rates are more normatively correct. Fourth, emerging market fundamentals are arguably more difficult to assess. Prior work argues that behavioral biases are stronger for such assets (Daniel, Hirshleifer, and Subrahmanyam, 1998, Hirshleifer, 2001; Kumar, 2009a). The sophistication effect we document is significantly larger for emerging market expectations, something one would expect if it indeed stemmed from a behavioral bias.

We also investigate potential alternative explanations to these results. First, advisor gender, a factor in our sophistication index, could influence return expectations via a number of mechanisms. While plausible in other settings, we show that such mechanisms are unlikely to explain our results. We nevertheless estimate all results with an alternative version of the sophistication index that does not include gender and the results remain highly significant. Second, although less likely for longer-term returns, a negative effect of sophistication could be specific to the time period of 2006 having fairly favorable past stock market performance. We address this issue by turning to additional data collected in 2009-2012, a period immediately following the global financial crisis of 2008, and covering the European debt crisis. Unlike the main data sample, we are unable to link these data to high-quality measures of advisor sophistication, but using other proxies produces results that support the main analysis. Third, 
our results could also arise if less sophisticated advisors feel they must compensate for their relative lack of skills by attracting clients with higher return promises. This is an intriguing hypothesis, but our data does not support it. As mentioned, advisers as a group do not appear to try to beat what they perceive to be the consensus forecast. Further, there is no such tendency among less sophisticated advisers. In fact, less sophisticated advisers are slightly further behind their perceived consensus compared to more sophisticated advisers. This suggests that less sophisticated advisers acquire and process information in a way that makes them simultaneously expect high returns, and believe that others expect even higher returns. Fourth, we find that sophisticated and more experienced advisers are less likely to leave the expected returns question blank in the survey. This is interesting in that it is consistent with the idea that advisers who self-select out of the sample likely have the most uninformative views, perhaps realizing this themselves. However, a Heckman selection model shows that this does not lead to biased estimates for the effect of sophistication.

The results of this paper also link to literature in the following areas. First, we contribute to the issue of determinants of return expectations. Using the data from UBS/Gallup surveys of U.S. individual investors' one-year return expectations in 1998-2002, Vissing-Jørgensen (2003) documents that more experienced investors, and those with over $\$ 100,000$ in financial assets have lower return expectations. This is consistent with our finding that financial sophistication reduces return expectations. Using data from the Michigan Survey of Consumers as well as the Health And Retirement Study (HRS), Dominitz and Manski (2004, 2007) find that younger respondents and men have more optimistic expectations, but their studies use data that is not 
readily comparable to ours. ${ }^{7}$ In addition to focusing on different questions, our paper differs from these studies in that we have professional subjects, obtain a very high response rate, are able to measure their financial sophistication, and analyze long-term expectations.

Our results also contribute to the issue of heterogeneity in expectations in general. A sufficient amount of disagreement among investors coupled with short sales constraints can also generate a price bubble (Miller, 1977; Harrison and Kreps, 1978; Chen, Hong, and Stein, 2002). Merton and Bodie (2005) argue that professionals' expectations are more homogenous since they tend to use similar data and methods. Earlier studies documenting diffuse expectations include Vissing-Jørgensen (2003) for laymen, Welch (2000) for financial economists, and Graham and Harvey (2012) for CFOs. With the exception of VissingJørgensen (2003) discussed earlier, these studies do not analyze the source of the crosssectional variation. While we find that sophistication is a strong predictor of expectations, substantial heterogeneity remains even after controlling for employer fixed effects, and even after limiting to a subsample of advisers who state that employer material is a key source on which they base their expectations (62\% of advisers). This shows that different interpretations of the same information are a major source of heterogeneity. One implication is that using professional advice may not substantially reduce the heterogeneity in investors' expectations.

\footnotetext{
7 This is due to three reasons. 1) Their survey question on return expectations starts by the line "We are interested in how well you think the economy will do in the next year". This might lead respondents to concentrate on their expectations regarding the real economy, possibly ignoring the fact that changes in market prices during a 12-month period primarily reflect changes in market expectations. 2) The question talks about "mutual fund shares invested in blue chip stocks like those in the Dow Jones Industrial Average", which adds another layer of complication and might lead the respondent one way or the other. 3) Instead of percentage return, they ask for a probability that fund shares in one year will be worth more than currently. As some indication that the respondents in those surveys may have quite uninformative views, over 30\% of the respondents give 50-50 chances.
} 
Finally, our paper relates to studies on financial advice and advisers, a topic of increasing recent interest. Expected returns are key inputs in asset allocation models (Damodaran, 2012) and advisers have a significant influence on investors' choices Campbell, 2006; Bluethgen et al. 2008; Mullainathan, Nöth, and Schoar, 2009). However, Bhattacharya et al. (2012) find that retail customers are reluctant to receive free unbiased financial advise, and that those who would most benefit from the advice are least likely to obtain it. Hong, Scheinkman, and Xiong (2008) study the asset pricing implications of financial advice in a model of heterogenous advisor ability.

In the remainder of the paper, section 2 presents the data, section 3 discusses the measurement of financial sophistication, and Section 4 presents the main results. Section 5 discusses additional issues related to sophistication and gender, and section 6 concludes.

\section{Data}

\section{A. Professional examination test scores}

We measure adviser ability using a unique objective measure, test score data from the Finnish Association of Securities Dealers' (FASD) ${ }^{8}$ professional examinations. The FASD maintains two investment services degrees: General Securities Examination (hereafter first level exam) and Investment Adviser Examination (second level exam). The objective of the examination system is to promote the financial knowledge in the industry, but the law does not require investment advisers to pass the examination. Passing rate in our sample period was

\footnotetext{
${ }^{8}$ FASD is a co-operation and self-regulatory organization of the Finnish investment services industry. Its members are brokers, dealers and other licensed financial service providers that engage in public securities trading by business.
} 
ca. $70 \%$, more recently passing rates have been as low as $60 \%$. This decline in passing rates probably reflects selection; earlier test takers were more sophisticated.

Our test score data includes all individuals who took the first level exam between its inception in 2000 and 2010. The first level exam covers basics of economics, financial statement analysis, financial instruments including derivatives, stock valuation, mutual funds, taxation and other securities regulation. The exam has 50 multiple choice questions (a correct answer gives 2 points, a wrong answer is penalized by 2 points) and three verbal questions each worth one point. Hence, the maximum score is 103 points and the minimum is -100 points. The points required for passing vary from one exam to another, but are usually in the range of 40 to 50 points.

Overall exam difficulty may vary slightly from one exam to another, and there is no scaling in the scores. Hence, the raw scores from one exam are not directly comparable to scores from another exam. We create a standardized $z$-score calculated by subtracting the test date mean score and then dividing by the test date standard deviation of the scores. A value of one in this metric means that the respondent received a test score one standard deviation above the test date mean score. We include all exam takers, including those who fail, in computing the means and standard deviations.

We link the test scores to a web survey of 742 financial advisers described in using adviser's names and their employers as link keys. With these link keys, we manage to match 694 out of the 742 advisers. We use the score from the first test taken by each adviser. As the survey only included advisers that have eventually passed the first level exam, those who failed their first attempt will have a score that is below passing level. An alternative is to use the highest score 
attained but we feel that the first score is a more pure measure of ability. ${ }^{9}$ The lowest raw test score we observe in the remaining sample is 24 points, and the sample $z$-score has an above zero mean. As only advisers who have passed the exam are included, our sample is tilted toward the relatively more sophisticated advisers.

\section{B. Web survey of financial advisers}

The web survey targeted 1,465 financial advisers who had passed the first level exam. Data from the survey were previously used by Kaustia, Laukkanen, and Puttonen (2009). They did not analyze the question we address, nor did they utilize the variables measuring return expectations. The survey was conducted in May 2006. It gathered 742 responses, corresponding to a response rate of $68 \%$. The data includes information on adviser demographics, expected returns, and self-perceived determinants of these expectations. Table 1 shows descriptive statistics on the sample demographics. Of the 742 respondents, $67 \%$ are females and $33 \%$ males. $^{10}$ An average adviser is 43.6 year old and has 6.3 years of work experience as a financial adviser. 20\% had also passed the second level exam during 2001-2006 and $53 \%$ of the respondents have a university or a college degree.

In the survey, the respondents were asked to supply a figure they would give their clients when asked about the expected annual return for European (EU-15) stocks and emerging markets stocks over the next 20 years. They were also asked to give their best guess on the figure

\footnotetext{
9 We have estimated our results also using the highest score instead of the first score, and the results are effectively unchanged.

10 Three respondents did not report their gender. These three were assigned a gender using the first name frequency database of the Finnish Population Register Centre - available at http://verkkopalvelu .vrk.fi/ nimipalvelu/default.asp?L=3. The gender of two respondents could be determined with a $100 \%$ likelihood and the third with a $99.99 \%$ likelihood based on recorded first name frequencies by age groups.
} 
other advisers would tell their clients to expect from European stocks. These expectatation are described in detail in section 4 .

After supplying the expected return figures the advisers were asked to respond to questions that may help explain what they base their return expectations on. Figure 1 shows the relative frequencies of the various data sources that the advisers reported using. The dominant information source is employer supplied material, comprising of investment strategy reviews and other internal reports. More than $30 \%$ of the respondents also stated that the business media and interest rates influence their return expectations.

The respondents were also asked to evaluate whether they perceive themselves as better, worse, or average in their competence of forecasting future returns compared to their peers. Overall, $10 \%$ of the respondents considered themselves as better, $12 \%$ as worse and $79 \%$ as average forecasters. The average confidence level does not suggest overconfidence nor underconfidence. Only $6 \%$ of women and as much as $17 \%$ of men consider themselves as better than average forecasters whereas $15 \%$ of women and only $5 \%$ of men think of themselves as worse than average in forecasting future stock market returns. Confidence in forecasting ability is positively correlated with having passed the second level exam. Better (worse) forecasters also report a higher (lower) than average number of information sources used as a basis for return expectations.

\section{Measuring adviser sophistication}

Sophisticated advisers have knowledge about economics, financial market institutions, assets, and regulations, as well as the analytical and cognitive capabilities to use and apply 
that knowledge in financial decision making. Our combined dataset has five measures that are plausibly correlated with the aspects of financial sophistication: first level exam test scores, whether the adviser has passed a second level exam (but no scores are available), the years of work experience as a financial adviser, general educational attainment, and gender.

The professional exams are designed to measure analytical skills in financial knowledge. As with all exams, the actual test scores reflect both the true abilities and knowledge of the exam takers but also contain some degree of noise. Many exam takers participate in prep courses or self-study to perform well in the exam, without necessarily being more financially sophisticated. Therefore, the test scores will give a noisy signal of financial sophistication. Similarly, passing the second level may be a noisy proxy of sophistication.

Advisers learn about financial markets and the institutions involved as they work in the business. The length of work experience will likely have learning curve effects: first year on the job teaches more than the second year, and so on. We use log of years of work experience to account for this effect. However, as we only have a cross-sectional sample of advisers, an additional year of experience may not be related to more sophistication. It could be that the more sophisticated advisers are promoted to other positions. Thus the more experienced advisers who we observe in data, may on average be less sophisticated than less experienced advisers included in our data. Therefore, experience is also a noisy signal of adviser sophistication.

General educational attainment is a proxy for analytical and cognitive skills. More educated advisers may also have better information acquisition and processing skills. We create a college dummy variable taking the value of one for advisers with a completed university or college 
degree. ${ }^{11}$ However, not all schools and universities are of equal quality, and perhaps even more importantly not all academic programs teach equally about financial and economic issues. Thus, advisers' academic background likely measures financial sophistication, but with some noise.

Chen and Volpe 2002) find a gender difference in financial literacy among college students, while controlling for the students' majors, class rank, work experience, and age. Lusardi and Mitchell (2008) document that women have a lower level of financial literacy among a broad cross-section of US near-retirement age and retirement age households (the Health and Retirement Study (HRS)). Using HRS data, we find that men also are significantly more often in charge of the household financial matters than women. ${ }^{12}$ Van Rooij, Lusardi, and Alessie (2011) document the gender gap in financial literacy in Dutch data, and show that it is is even greater in advanced financial literacy. Almenberg and Säve-Söderbergh (2011) find a similar large gender difference in Swedish data. These two studies use data from countries that are close to Finland in terms of institutions and culture.

This population-wide sophistication difference may to some extent also apply to financial advisers. In our adviser sample, men perform better in professional exams, they receive on average 2.4 points more than women do in the first level professional exam. $27 \%$ of men have

\footnotetext{
${ }^{11}$ About half of each age cohort in Finland graduate from three-year junior-colleges (Gymnasia) qualifying them towards M.Sc. degree granting university studies. We assign college dummy $=1$ also to these respondents even if they had not completed a higher academic degree at the time of the survey. The main results are nevertheless similar if we assign college dummy $=0$ to them instead.

12 Within HRS households consisting of a male and female couple, $60 \%$ of the households assign the male as the respondent to financial questions, while more than $80 \%$ of the housholds assign the female as the respondent of family related questions. Even in households where women earn over $\$ 10,000$ more than their spouses and controlling for age differences, the men are more often the financial respondents.
} 
passed the second level exam compared to $16 \%$ of women. Further, the fact that two thirds of advisers, in an otherwise male-dominated industry, are women is consistent with more sophisticated employees advancing to other positions. Thus, we believe that the adviser gender noisily measures financial sophistication.

As the five variables (test score, 2nd level exam, college dummy, log experience, and gender) likely measure different aspects of sophistication, we wish to extract the common variation in them to use as a sophistication measure. Table 2 shows the cross-correlations between these five variables. Most of the cross-correlations are statistically significant. The exception is log experience, which is not correlated with any of the variables at the $5 \%$ significance level.

We use factor analysis to extract the common variation in the sophistication proxies. ${ }^{13}$ Factor analysis yields $k$ factors linearly transformed from the $p$ proxy variables where $k<p$ such that the resulting factors explain the maximum amount of the observed variance in the proxy variables. Effectively we condense all the information in the proxy variables in a way that retains the maximum amount of information. Since the common information in the sophistication proxies is the easiest to condense, the resulting factor mostly reflects the common variation, which we argue measures sophistication.

When we include all five sophistication proxies $(p=5)$ to create a one factor $(k=1)$ output, the factor loading of log experience is almost zero. As already noted, the statistically insignificant correlation of experience with the other proxies makes it a worse candidate for factor analysis. ${ }^{14}$ As previously discussed, there are reasons suggesting that experience may

\footnotetext{
13 A similar approach is used, e.g., by Baker and Wurgler 2006) in creating their investor sentiment index.

14 Formally, the Keyser-Meyer-Olkin measure of sampling adequacy for log experience is below the acceptable
} 
not measure sophistication in these data. We therefore drop log experience variable and use the other four sophistication proxies ( $p=4$ ) to create a factor to capture the common variation.

The absolute loadings of the four factors are roughly equal. Gender and college dummies receive slightly more weight than the two professional exam related attributes. As the crosscorrelation results from Table 2 indicate, gender ( female $=1$, male $=0$ ) receives a negative factor loading, while the other three receive a positive factor loading. We believe that the common variation in these four variables is correlated with the financial sophistication of the adviser and that the resulting factor proxies for unobserved sophistication. We denote it by sophistication composite index. ${ }^{15}$

Next we relate the sophistication composite index to advisers' self perceived ability to form rational return expectations, as well as the sources of information they use in forming these expectations. We run logit regressions where the dependent variable indicates particular self perceived ability (such as above average), or with the analysis of information sources, indicates using particular source. In addition to the sophistication index, the regressions include control variables (advisor age and length of work experience, and in the case of information sources, dummies for below and above average forecasting ability).

Ex ante, we would expect sophistication to be positively related to self-perceived ability, as well as to using interest rates, economic statistics and ratios, and outside strategy reviews as information sources. Interest rates and economic statistics are key inputs in forward-looking

threshold of 0.5 . Linear and quadratic work experience also inadequately explain common variance.

15 This sophistication index is highly correlated with a naïve index constructed by summing over the set of standardized proxy variables with equal weights. All of the subsequently reported results are very similar if we use equal weighting instead. 
forecasts of equity returns. Using outside strategy reviews, on the other hand, could be a proxy for being generally more informed. The results reported in Table 3 by and large confirm these predictions. Panel A shows that sophistication and self-perceived ability are significantly positively related. Panel B deals with information sources. The relation is positive and statistically significant (at $5 \%$ level) for interest rates and economic statistics. It is also positive and statistically significant for outside strategy reviews in a univariate test, but in the full model the t-statistic drops to 1.2. While the other information sources (employer material, financial media, discussions with colleagues, and historical returns) could all potentially receive positive weights when formulating a rational forecast, we do not expect them to be strongly related to sophistication in our context. In line with these expectations, Panel B of Table 3 shows that those effects are all insignificant.

In addition to the analysis of the correlations between the sophistication index components discussed earlier, the analysis in Table 3 provides additional confirming evidence of the validity of our sophistication index.

\section{Results}

\section{A. Univariate analysis}

Table 4 shows univariate results on advisers' return expectations. The advisers expect the European market to return $10.1 \%$ per annum over the next 20 years, which is close to the realized 20-year historical return of $11.6 \%$ at the time of the survey. At the time of the survey the European stock markets (MSCI Europe) had produced a $24.2 \%$ per annum return over the most recent three years, but the markets had just gone down by $2.6 \%$ in May. Thus, advisers 
responded to the questionnaire in a market situation with low recent returns but high past returns over longer horizons. At the time of the survey, 10-year government bonds had a yield of $4.0 \%$, so the expected long term return of $10.1 \%$ implies an equity premium of $6.1 \%$.

Regarding emerging market stocks the advisers expect a return of $15.4 \%$ per annum, i.e., $5.3 \%$ more than from European stocks. ${ }^{16}$ At the time of the survey, emerging markets had provided a return of $14.4 \%$ for 18 -year history. However, the past 5-year return had been $21.1 \%$ per annum. Consistent with the higher volatility of historical returns, the cross-sectional standard deviation for the advisers' emerging market expectations at $9.8 \%$ is double the $4.8 \%$ standard deviation for the European stock market expectations. For comparison, the crosssectional standard deviation for individual investors' one-year forecasts reported by VissingJørgensen (2003) is 10.3\%. For expert samples (and longer forecast horizons), Welch (2000) reports a standard deviation of $2.1 \%$ for the 30 -year returns by $\mathrm{PhD}$ level financial economists, and Graham and Harvey (2012) report a (time average) standard deviation of $2.8 \%$ for the 10 year market risk premium estimates by CFOs of US firms.

Some advisers did not want to give an expected return figure, and we excluded some unrealistically high expectations as outliers. If we truncate the expected returns that exceed $25 \%$ per annum, the mean European expectation decreases by 0.6 percentage points to $9.5 \%$, and the Emerging market expectation decreases by 2.5 percentage points to $12.9 \%$. The

\footnotetext{
${ }_{16}$ What should the emerging market premium be? Damodaran 2012) suggests that volatility ratios should be roughly equal to risk premium ratios. Using the full 18 years of history available on May 31, 2006 for the MSCI Emerging Market monthly gross return index, we find that the monthly standard deviation is $6.69 \%$ for emerging market stocks and $4.60 \%$ for European stocks. Based on the volatility ratio, the implied risk premium for the emerging market stocks should then be $8.9 \%\left(=6.1 \% \times \frac{6.69 \%}{4.60 \%}\right)$, or 2.8 percentage points greater than for European stocks.
} 
emerging market premium in these truncated data is $12.9 \%-9.5 \%=3.4 \%$, close to a figure obtained using historical volatility ratios (2.8\%, see footnote 16$)$.

For a more in depth view of the dispersion, Figure 2 shows kernel density estimators of the return expectations. ${ }^{17}$ In addition to the raw returns, the graph shows the residuals from a linear regression model, and we will return to those results later. The interquartile ranges are $2 \%$ for the European markets and $5 \%$ for the emerging markets. The difference in return estimate a client gets from a 75th percentile adviser compared to a 25 th percentile implies a $44 \%$ difference in expected final wealth in 20-year investments for European markets and a $143 \%$ difference for emerging markets.

On average the financial advisers believe that their peers have higher expectations than they do themselves. This false-consensus effect is similar to what Welch (2000) finds among academic economists. The gap between the perceived consensus on European stock returns $(12.0 \%)$ and the real consensus $(10.1 \%)$ is highly significant (t-test $p<0.001$, Wilcoxon $p<$ $0.001)$.

\section{B. Determinants of return expectations}

In this section we discuss the results of our main research question, that is, can financial sophistication explain the heterogeneity in return expectations? Figure 3 plots average expected returns by sophistication quintiles. Expected returns are monotonically decreasing by increasing sophistication for both the European and emerging markets. The slope of the relation is steeper for emerging market expectations.

17 The kernel density bandwidth is chosen to smooth the raw returns to account for fact that most respondents gave their estimate as a round percentage point figure. 
We estimate the size of this sophistication effect on expected returns by regressing the advisers' return expectations on the sophistication index including demographics, selfperceived forecasting ability, and employer fixed effects as controls. The results for European stock market return expectation regressions are shown in Table 5

Model (1) includes only the sophistication index, controlling for employer fixed-effects. Sophistication is a strongly significant determinant of adviser expectations. Model (2) adds the natural log of years of experience as financial adviser to the model. Missing experience data reduces the sample size by $10 \%$. The estimated experience effect is not economically nor statistically significant. Model (3) adds the log of the adviser age. The estimated effect is positive but statistically insignificant. Also, the marginal age effect at the mean of the age distribution, 43.6 years, is only $0.04(=1.6 / 43.6)$ percentage points. For robustness, we have estimated the model allowing for quadratic age effects and the effects are also statistically insignificant. Model (4) adds self-perceived forecast ability. Self-identified worse forecasters are significantly more pessimistic in their expectations. A worse forecaster has 1.7 percentage points lower long term expectations that average or better forecasters. However, selfperception of being above average forecaster is not correlated with having higher expectations. Controlling for all the additional factors, the sophistication effect remains highly statistically significant. A one standard deviation increase in the sophistication index reduces the expected stock return by 1.1 percentage points.

Table 6 reports corresponding estimates for emerging market stock return expectations. Compared to European expectations, sophistication has a stronger effect in emerging market expectations. A one standard deviation increase in the sophistication composite index reduces 
the return expectation by 2.3 percentage points. This is consistent with the view that behavioral biases are stronger for assets that are harder to value (Daniel, Hirshleifer, and Subrahmanyam. 1998; Hirshleifer, 2001; Kumar, 2009a). The negative effect of work experience is stronger for emerging market expectations, but not statistically significant. Adviser age is now statistically significant: older advisers appear to have higher expectations for emerging market returns. For an adviser of mean age of 43.6 years, the marginal effect of an additional year of age is 0.14 $(=6.0 / 43.6)$ percentage points. An extra year of age for most advisers also involves an extra year of work experience, and these would cancel each other on average.

In sum, the results of this section provide strong confirming evidence for the hypothesis that financial sophistication and long-term stock market return expectations are negatively related.

\section{Remaining heterogeneity}

The main results of this paper point to an important role for financial sophistication in moderating return expectations. Substantial heterogeneity nevertheless remains after accounting for this effect. The different model specifications in Table 5 explain $7.6 \%$ to $8.3 \%$ of the variation in the European expectations as measured by adjusted R-squared. The gray columns show the decomposed adjusted R-squared contributions of each explanatory variable using the Shorrocks (1999) Shapley value method. The sophistication index contributes $60 \%$ and employer fixed-effects contribute roughly $25 \%$ to the model goodness-of-fit.

The distribution plot in Figure 2 shows, in addition to raw expected returns, kernel density estimates of the residuals from a linear model explaining expected returns with sophistication, experience, age, and employer effects. The residuals plotted in the graph 
have been translated to have a mean equal to the raw return mean. While the raw return expectations have a left-skewed and peaked distribution, the residuals are clearly closer to normally distributed. However, controlling for the covariates hardly reduces the interquartile range of the distribution.

The dashed curve in the graph uses a subsample of only those advisers who use employer supplied information as a primary source for basing their expectations on. This distribution is practically identical to the one for the unrestricted sample. This shows that advisers employed by the same bank and using the same primary information source have widely different longterm expectations. This is consistent with models of Harris and Raviv (1993) and Kandel and Pearson (1995) where heterogeneity is driven by individuals' different interpretations of the same information.

\section{Robustness checks and alternative explanations}

Table 7 collates estimation results for alternative and additional specifications for demonstrating robustness of the shown results.

\section{A. Modeling unobserved heterogeneity}

The first three models of Table 7 estimate the determinants of pooled European and emerging market stock return expectations. Model (2) allows for random adviser effects, while model (3) estimates fixed adviser effects. The adviser fixed effects model results are robust to any omitted variables that would equally impact the level of European and emerging market expectations. The emerging market dummy captures the average difference between the expected return of emerging market stocks and European stocks. The interaction term 
between the emerging market dummy and the sophistication index measures the additional impact of the sophistication effect on the emerging market expecatations over and above the sophistication effect on European return expectations. A one standard deviation increase in the sophistication index reduces emerging market expectations by 1.6 to 1.8 percentage points more than it reduces european return expectations.

While the adviser fixed effect captures all adviser related effects such as adviser sophistication, age, and experience, the random effects model allows for estimating these effects. The estimated effects of emerging market premium and sophistication interaction are practically equal. A Hausman test of the random effects versus fixed effects model can not reject the consistency of the random effects model. The estimated sophistication effect at 0.9 percentage points per one standard deviation change is of same magnitude to baseline mode reported in Table 5. Adviser age appears to have a statistically significant effect on the expected returns, while the log experience has a negative but statistically insignificant effect.

\section{B. Non-response to the survey question on expected returns}

In the survey, $69 \%(66 \%)$ of the queried advisers reported their return expectations for the European (emerging) markets. The response rates increase when we restrict our sample to those advisers for whom we have a full set of control variables available. The European expectations response rate is now $80 \%$ and emerging market response rate is $77 \%$.

Models (4) and (5) explore the determinants of the likelihood of responding to the expected returns question. Adviser sophistication could be hypothesized to both increase and decrease response likelihood. On one hand, as giving a point estimate for stock returns is difficult, it could be that sophisticated advisers decline from giving a number, especially for a more 
unknown asset class such as the emerging markets. On the other hand, less sophisticated advisers may believe that as they lack the skills and knowledge of their more sophisticated peers, they should not give a return forecast figure to their clients even if specifically prompted.

The estimated results indicate that sophistication increases response rate. A one standard deviation increase in sophistication for an average adviser corresponds to a marginal probability increase of 5.9 (6.2) percentage points for European (emerging market) response rate. Experience appears to also increase the likelihood of responding: for an average adviser an additional year of experience increases the reponse likelihood 1.9 percentage points for European stock returns (1.5 percentage points for emerging market returns).

Given that the choice of responding to the question is explained by sophistication and experience, we estimated a Heckman two-step model to check whether the response selection could bias our estimates of sophistication effects on expected returns. Having the sophistication composite index and the log experience in the selection equation, the estimated inverse Mills ratio is statistically insignificant for both European and emerging market return expectations. Thus, we believe that selection effects due to sophistication and experience do not significantly bias our earlier results.

\section{Gender and selection effects}

Our baseline models explaining adviser expected returns include gender as a component of financial sophistication index. But what if gender affects return expectations through other channels than sophistication? Prior research has shown gender differences in overconfidence, optimism, deception, risk preferences, and career dynamics.

A gender difference in general optimism could cause a difference in stock return 
expectations. However, prior studies show that men tend to be more optimistic. Barber and Odean (2001) find that men are more overconfident than women. Dominitz and Manski (2004) argue that men are more optimistic in expecting stocks to yield positive returns. Green, Jegadeesh, and Tang (2009) report that female equity analysts are less optimistic in their earnings forecasts than male analysts. Gender-related general optimism should therefore lead to female advisers expecting lower returns which is not what we find.

Could female advisers be more prone to exaggerate return expectations to their clients to boost sales? This seems unlikely as prior studies show that women generally behave more ethically (Kasipillai and Jabbar, 2006) and are less likely to lie (Dreber and Johannesson, 2008. Erat and Gneezy, forthcoming) compared to men.

Gender differences in risk tolerance could cause a difference in return expectations under some conditions. A highly risk averse female adviser with low return expectations would be unlikely to invest in risky assets herself and hence might make a bad saleswoman. Given that the job requires selling equity products, female advisers who select into the profession may come disproportionately from the right tail of the distribution of return expectations. Another possible mechanism involves the risk averse advisers updating their expected returns to conform to employer created incentives. Thus, gender difference in risk preferences might cause a difference in expectations in the adviser sample.

However, Croson and Gneezy (2009) point out that selection into the profession and updating of preferences in finance professionals are also likely to reduce the gender difference in risk preferences. E.g. Dwyer, Gilkeson, and List (2002) find that in a sample of mutual fund investors controlling for investor knowledge on financial markets and investments 
substantially explains the gender difference in risk aversion. The selection story is also not supported by our data in that the majority of the advisers are in fact women.

The finance profession is traditionally viewed as male dominated. Kumar (2010) finds that stock markets react more strongly to estimates and recommendations made by female analysts. He argues that this is due to markets recognizing discrimination against hiring women. If the profession favors an optimistic outlook in promotion, but imposes a glass ceiling for women, optimistic males will be promoted out of the adviser sample. Then the adviser sample would include both pessimistic men and women, but only optimistic women. In this case the sophistication index constructed using gender would proxy for career dynamics related effects in expectations. However, we find no support for this career dynamics story in the data. As more senior advisers are more likely to be promoted before junior advisers, this career effect should be stronger for a subsample of more experienced advisers. But this is not what the data shows: The gender gap in return expectations is conversely wider for inexperienced advisers.

For robustness, we nevertheless estimate all the expected return results with a version of the sophistication index that does not include the gender variable. The results shown in Table 8 are qualitatively similar to the baseline results in that sophistication significantly reduces return expectations. However, quantitatively the effect is somewhat weaker, particularly for European market expectations. The full model coefficient is reduced by $34 \%$ (26\%) for European (emerging market) expectations compared to the baseline estimates. In these specifications a separate statistically significant gender dummy picks up all of the gender effect.

We partition the sample into sophistication terciles and run the regressions from Table 8 in these subsamples. Figure 4 shows the gender effect estimates for these regressions. The 
coefficient of the gender dummy decreases monotonically when moving from the lowest to the highest sophistication tercile, and is no longer statistically significant in the highest tercile (nor in the middle tercile with emerging markets). This is consistent with the idea that gender is associated with financial sophistication among relatively less sophisticated individuals, in line with studies that find a gender effect in the general population (Chen and Volpe, 2002; Lusardi and Mitchell, 2008; van Rooij, Lusardi, and Alessie, 2011). If the gender effect is due to a cultural bias, it makes sense that the effect would diminish when sophistication increases, which is what we find.

\section{The role of market conditions}

The relation between return expectations and sophistication could plausibly be expected to be positive under some market conditions. For example, if the opinion of less sophisticated investors fluctuates more with the market sentiment, in a low sentiment period the less sophisticated investors could grow excessively pessimistic, perhaps due to extrapolating from recent low returns. The more sophisticated would then have higher return expectations in such periods. Sophistication and expectations could be positively related also when savvy investors perceive that a bubble is about to inflate due to noise traders' future demand, as in models of rational speculation such as DeLong et al. (1990). We wish to note, however, that shortterm expectations should be more susceptible to such effects compared to the 20 -year return expectations used in our analysis.

To address this issue we obtain another data set of advisor return expectations from early 2009 to 2012. The global financial crisis preceding these years, and to some extent the European debt crisis beginning in 2010, make this period very different from the period leading to spring 
2006 when the earlier data on expectations was collected. These data are collected in 14 separate financial adviser seminars occurring on different dates from a total of 254 individuals. Each seminar has 15 to 20 participants, and the response rate is virtually $100 \%$. Similar to the main data, all subjects have passed the first level exam. A drawback of these data is that we must rely on more noisy measures of sophistication. We designate those advisers as experts who 1) have a job title containing the word private banker, manager, or analyst, 2) have two or more years of work experience, and 3) do not make a logical mistake in a simple probability assessment task. ${ }^{18}$ This produces 58 experts, representing $23 \%$ of the sample. Another difference is that the return expectations questions are not exactly comparable to those in our main data. The new surveys do not include a question on European stock returns nor ask for 20-year returns, but they do ask for 10-year expected returns for emerging markets.

Table 7 model (6) shows the results from a regression explaining return expectations with a sophistication factor comprising of the common variation in the expert dummy discussed above and adviser gender dummy, as well as fixed time effects for each seminar. The sophistication effect is both statistically and economically significant. A one standard deviation increase in this alternative sample sophistication measure decreases expected 10year emerging market returns by 0.9 percentage points.

Alternatively the expert and adviser gender effects can be separately estimated. The coefficient estimate for the expert dummy indicates that experts' return expectations are 1.1

\footnotetext{
${ }_{18}$ The survey contains other questions related to stock market expectations. One of them asks for the respondent to estimate the probability that the market goes up by more than $20 \%$ in the next six months, and the next question asks for the probability that the market goes down by more than $20 \%$ in the next six months. Some subjects give probabilities that sum up to $100 \%$, effectively implying a zero probability of the market staying within $+/-20 \%$ of current level. We classify this as a mistake.
} 
percentage points lower compared to nonexperts. The t-value of the coefficient is -1.7 , making it just significant at the $10 \%$ level. The separate gender dummy again indicates that women have higher return expectations.

All in all, the results from these data provide added confirmation to the idea that the first order effect of sophistication is to reduce the incidence of excessively high long-term return expectations, irrespective of market conditions.

\section{E. Adviser incentives}

Advisers responding to the web survey asking for return expectations were entered into a lottery in which five individuals were randomly drawn to win a book written by one of the authors. In addition, an executive summary of the survey results was emailed to them. While this might have motivated some people to participate in the survey, no extrinsic incentives were provided to promote accurate and truthful answers. This would have been impossible in practice, as the survey was asking for 20-year return expectations. We do not believe that lack of such explicit incentives would have a significant impact on our results. Prior literature finds that the presence of financial incentives improves performance in tasks where one needs to pay close attention (such as memory- and recall-related tasks) and in dull tasks where intrinsic motivation may be low (such as coding words). In other types of tasks, the presence or absence of direct monetary incentives in surveys and experiments rarely make a difference (for reviews, see Camerer and Hogarth, 1999: Gneezy, Meier, and Rey-Biel, 2011). We are asking for figures that are central in the respondents everyday work, and the respondents likely have high intrinsic motivation regarding such issues. ${ }^{19}$ The very high response rate $(68 \%)$ we achieve

19 Direct experience by two of the authors actively working in educating similar audiences supports these claims. 
ensures that the sample is not only picking up respondents having unusually high motivation to answer.

Advisor incentives could also interact with sophistication and return expectations. In the model of Hong, Scheinkman, and Xiong (2008) more sophisticated advisers (the tech-savvies) strategically signal their quality by overinflating their recommendations to differentiate themselves from less knowledgable advisers (the old fogies). Smart investors can debias such advice, but naïve investors are unable to do so and so a bubble may form. We do not see such an effect in our data, as we find, contrary to Hong et al., that more sophisticated advisers have lower return expectations. Their model is particularly motivated by technological innovations, and one can think of emerging markets as representing such new growth oriented investment opportunities. However, our results there are similar and even stronger: more sophisticated advisers have lower return expectations. The practical setting primarily motivating Hong et al. is the matching process between analysts and institutional investors. Our setting of personal financial advisers and retail clients likely involves a very different matching mechanism, and thus we do not see our results as directly refuting Hong et al.

Another possibility is that less sophisticated advisers quote higher return expectations to their clients in order to remain competitive with their more sophisticated counterparts. This is an intriguing hypothesis, and the data allows addressing it by way of comparing advisers' expectations to what they perceive their peers to expect. Specifically, this skill-compensation hypothesis predicts that less sophisticated advisers would have higher expectations relative to their perceived consensus. This is not what we find, however. Advisers who are below median in sophistication, on average expect returns of 2.2 percentage points lower than their perceived 
consensus. The corresponding number for above-median advisers is 1.6. An OLS regression controlling for other factors confirms these findings. If anything, sophistication increases expected returns relative to the perceived consensus, though the effect is not significant (tvalue 1.4). These results do not support the skill-compensation hypothesis.

\section{Conclusions}

This paper combines data from financial advisers' professional exam scores with other variables from a survey to create an index of financial sophistication. We find that a one standard deviation increase in the sophistication index reduces expected annualized 20-year European (emerging market) stock returns by 1.1 (2.3) percentage points. The sophistication effect contributes more than $60 \%$ to the model fit, while the employer fixed effects contribute $20 \%$ to $25 \%$. These results are consistent with naïve investors having excessively optimistic expectations, which is thought to be a potential ingredient in asset price bubbles. Furthermore, our results are stronger for emerging market expectations, consistent with hard to value assets being more affected by behavioral biases. Given the nature of our sophistication measures, there is good reason to believe that the relation we document at least partially reflects a causal effect. But there are other interesting possibilities as well. For example, a latent personality trait could make people more likely to acquire financial sophistication and simultaneously create a tendency to form more moderate expectations. We leave the analysis of such mechanisms for future work.

Our composite measure of financial sophistication included gender as one component, based on robust evidence in earlier research showing that women have lower levels of financial 
literacy in the general population. Self-selection into the profession and potential career dynamic effects, combined with a gender difference in risk aversion, could be potential confounding factors. The available data does not support such effects, but as a robustness check we construct a sophistication index without the gender variable. The main results remain qualitatively similar in that sophistication is significantly associated with lower return expectations, but the point estimates imply a slightly smaller effect. Part of the explanatory power in the baseline model is then picked up by a statistically significant gender effect.

While financial sophistication appears to be an important factor explaining the heterogeneity in return expectations, substantial unexplained dispersion nevertheless remains. Employer fixed effects do not markedly reduce this dispersion, nor do controls for type of information used. The full regression model explains $8 \%(12 \%)$ of the variance in the European (emerging market) return expectations. This shows that different interpretations of the same information are a major source of heterogeneity in expectations.

Improving household financial decision making by supplying unbiased financial information and sound advise is not an easy task. Bhattacharya et al. (2012) find that household clients are reluctant to receive unbiased and costless financial advise, and that those who do opt to receive the advise, tend not to act on it. In addition to this 'downstream' problem in the supply chain of information, we pinpoint an 'upstream' problem: advisers add a heterogenous component to their employer supplied financial information. Thus, households receive heterogenous financial information that is partially explained by adviser specific systematic biases. 


\section{References}

Agnew, J. R., 2006. Do behavioral biases vary across individuals? evidence from individual level 401 (k) data. Journal of Financial and Quantitative Analysis 41, 939-962.

Almenberg, J., Säve-Söderbergh, J., 2011. Financial literacy and retirement planning in Sweden. Journal of Pension Economics and Finance 10, 585-598.

Baker, M., Wurgler, J., 2006. Investor sentiment and the cross-section of stock returns. Journal of Finance 61, 1645-1680.

Barber, B., Odean, T., 2001. Boys will be boys: Gender, overconfidence and common stock investment. Quarterly Journal of Economics 116, 261-290.

Bhattacharya, U., Hackethal, A., Kaesler, S., Loos, B., Meyer, S., 2012. Is unbiased financial advice to retail investors sufficient? Answers from a large field study. Review of Financial Studies 25, 975-1032.

Bluethgen, R., Gintschel, A., Hackethal, A., Müller, A., 2008. Financial advice and individual investors' portfolios. Working paper, European Business School, Deutsche Bank and Goethe University.

Calvet, L. E., Campbell, J. Y., Sodini, P., 2009. Measuring the financial sophistication of households. American Economic Review: Papers and Proceedings 99, 393-398.

Camerer, C. F., Hogarth, R. M., 1999. The effects of financial incentives in experiments: A review and capital-labor production framework. Journal of Risk and Uncertainty 19, 7-42.

Campbell, J. Y., 2006. Household finance. Journal of Finance 61, 1553-1604.

Chen, H., Volpe, R. P., 2002. Gender differences in personal financial literacy among college students. Financial Services Review 11, 289-307.

Chen, J., Hong, H., Stein, J. C., 2002. Breadth of ownership and stock returns. Journal of Financial Economics 66, 171-205.

Christelis, D., Jappelli, T., Padula, M., 2010. Cognitive abilities and portfolio choice. European Economic Review 54, 18-38.

Claus, J., Thomas, J., 2001. Equity premia as low as three percent? evidence from analysts' earnings forecasts for domestic and international stock markets. The Journal of Finance 56, 1629-1666.

Cronqvist, H., Siegel, S., 2012. Why do individuals exhibit investment biases? Working paper. 
Croson, R., Gneezy, U., 2009. Gender differences in preferences. Journal of Economic Literature $47,448-474$.

Damodaran, A., 2012. Equity risk premiums (ERP): Determinants, estimation and implications - the 2012 edition. Working paper.

Daniel, K., Hirshleifer, D., Subrahmanyam, A., 1998. Investor psychology and security market under-and overreactions. Journal of Finance 53, 1839-1885.

DeLong, J. B., Shleifer, A., Summers, L. H., Waldmann, R. J., 1990. Positive feedback investment strategies and destabilizing rational speculation. Journal of Finance 45, 379-395.

Dhar, R., Zhu, N., 2006. Up close and personal: Investor sophistication and the disposition effect. Management Science 52, 726-740.

Dominitz, J., Manski, C. F., 2004. How should we measure consumer confidence? Journal of Economic Perspectives 18, 51-66.

Dominitz, J., Manski, C. F., 2007. Expected equity returns and portfolio choice: Evidence from the health and retirement study. Journal of European Economic Association 5, 369-379.

Donaldson, R. G., Kamstra, M. J., Kramer, L. A., 2010. Estimating the equity premium. Journal of Financial and Quantitative Analysis 45, 813-846.

Dreber, A., Johannesson, M., 2008. Gender differences in deception. Economics Letters 99, 197199.

Dwyer, P. D., Gilkeson, J. H., List, J. A., 2002. Gender differences in revealed risk taking: Evidence from mutual fund investors. Economics Letters 76, 151-158.

Erat, S., Gneezy, U., forthcoming. White lies. Management Science.

Fama, E. F., French, K. R., 2002. The equity premium. The Journal of Finance 57, 637-659.

Feng, L., Seasholes, M., 2005. Do investor sophistication and trading experience eliminate behavioral biases in financial markets? Review of Finance 9, 305-351.

Gneezy, U., Meier, S., Rey-Biel, P., 2011. When and why incentives (don't) work to modify behavior. Journal of Economic Perspectives 25, 191-210.

Goetzmann, W. N., Kumar, A., 2008. Equity portfolio diversification. Review of Finance 12, 433463.

Graham, J. R., Harvey, C. R., 2012. The equity risk premium in 2012. Working paper, Duke University. 
Green, C., Jegadeesh, N., Tang, Y., 2009. Gender and job performance: Evidence from Wall Street. Financial Analysts Journal 65, 65-78.

Grinblatt, M., Ikäheimo, S., Keloharju, M., Knüpfer, S., 2012. IQ and mutual fund choice. Working paper.

Grinblatt, M., Keloharju, M., Linnainmaa, J., 2011. IQ and stock market participation. Journal of Finance 66, 2121-2164.

Haigh, M. S., List, J. A., 2005. Do professional traders exhibit myopic loss aversion? An experimental analysis. Journal of Finance 60, 523-534.

Harris, M., Raviv, A., 1993. Differences of opinion make a horse race. Review of Financial Studies $6,473-506$.

Harrison, G. W., List, J. A., 2004. Field experiments. Journal of Economic Literature 42, 10091055.

Harrison, J. M., Kreps, D. M., 1978. Speculative investor behavior in a stock market with heterogeneous expectations. Quarterly Journal of Economics 92, 323-336.

Hirshleifer, D., 2001. Investor psychology and asset pricing. Journal of Finance 56, 1533-1597.

Hoch, S. J., 1984. Conterfactual reasoning and accuracy in predicting personal events. Journal of Experimental Psychology 11, 719-731.

Hong, H., Scheinkman, J. A., Xiong, W., 2008. Advisors and asset prices: A model of the origins of bubbles. Journal of Financial Economics 89, 268-287.

Kandel, E., Pearson, N. D., 1995. Differential interpretation of public signals and trade in speculative markets. Journal of Political Economy 103, 831-872.

Kasipillai, J., Jabbar, H. A., 2006. Gender and ethnicity differences in tax compliance. Asian Academy of Management Journal 1, 73-88.

Kaustia, M., Alho, E., Puttonen, V., 2008. How much does expertise reduce behavioral biases? The case of anchoring effects in stock market estimates. Financial Management 37, 391-411.

Kaustia, M., Laukkanen, H., Puttonen, V., 2009. Should good stocks have high prices or high returns? Financial Analysts Journal 65, 55-62.

Kumar, A., 2009a. Hard-to-value stocks, behavioral biases, and informed trading. Journal of Financial and Quantitative Analysis 44, 1375-1401.

Kumar, A., 2009b. Who gambles in the stock market? Journal of Finance 64, 1889-1933. 
Kumar, A., 2010. Self-selection and the forecasting abilities of female equity analysts. Journal of Accounting Research 48, 393-435.

List, J. A., 2003. Does market experience eliminate market anomalies? Quarterly Journal of Economics 118, 41-71.

Lusardi, A., Mitchell, O. S., 2008. Planning and financial literacy: How do women fare? American Economic Review: Papers and Proceedings 98, 413-417.

McFadden, D., 1974. Conditional logit analysis of qualitative choice behavior. In: Zarembka, P. (Ed.), Frontiers of Econometrics. New York: Academic Press, pp. 105-142.

Merton, R. C., Bodie, Z., 2005. Design of financial systems: Towards a synthesis of function and structure. Journal of Investment Management 3, 1-23.

Miller, E. M., 1977. Risk, uncertainty, and divergence of opinion. Journal of Finance, 1151-1168.

Mullainathan, S., Nöth, M., Schoar, A., 2009. The market for financial advice: An audit study. Working paper, Harvard University, University of Hamburg and MIT.

Puri, M., Robinson, D. T., 2007. Optimism and economic choice. Journal of Financial Economics 86, 71-99.

Rantapuska, E., Knüpfer, S., 2008. Which investors leave money on the table? Evidence from rights issues. Review of Finance 12, 701-733.

van Rooij, M., Lusardi, A., Alessie, R., 2011. Financial literacy and stock market participation. Journal of Financial Economics 101, 449-472.

Seru, A., Shumway, T., Stoffman, N., 2010. Learning by trading. Review of Financial Studies 23, 705-739.

Shiller, R. J., 1984. Stock prices and social dynamics. Brookings Papers on Economic Activity 1984: 2, 457-498.

Shiller, R. J., 1990. Market volatility and investor behavior. American Economic Review 80, 5862.

Shorrocks, A. F., 1999. Decomposition procedures for distributional analysis: A unified framework based on the Shapley value. Mimeo: University of Essex.

Vissing-Jørgensen, A., 2003. Perspectives on behavioral finance: Does "irrationality" disappear with wealth? Evidence from expectations and actions. NBER Macroeconomics Annual, 139194. 
Weinstein, N. D., 1980. Unrealistic optimism about future life events. Journal of Personality and Social Psychology 39, 806-820.

Welch, I., 2000. Views of financial economists on the equity premium and on professional controversies. Journal of Business 73, 501-537. 


\section{Table 1: Descriptive statistics}

The background variables of the financial advisers surveyed. All advisers have passed a first level professional exam. Test score refers to the score from the first level exam. $\dagger$ denotes dummy variables. The three education dummies denote the highest level of educational attainment, i.e. the high school diploma dummy for a university graduate equals zero. The sophistication composite index is a proxy of unobservable sophistication derived from factor analysis of the test score, passed 2nd level exam, and the education dummies. Panel A shows the descriptive statistics for the full sample, Panel B for subsample of Men, and Panel C for subsample of Women. A total of 742 financial advisers were surveyed.

Panel A - All

\begin{tabular}{lcccccc}
\hline & Mean & St.Dev. & Median & Min & Max & N \\
\hline Female $\dagger$ & 0.67 & 0.47 & 1 & 0 & 1 & 742 \\
Age (in years) & 43.6 & 9.1 & 44 & 23 & 64 & 740 \\
Experience (in years) & 6.3 & 5.6 & 5 & 0 & 33 & 591 \\
Test score & 55.7 & 11.4 & 56 & 16 & 99 & 694 \\
Passed 2nd level exam $\dagger$ & 0.20 & 0.40 & 0 & 0 & 1 & 742 \\
University degree $\dagger$ & 0.25 & 0.43 & 0 & 0 & 1 & 730 \\
College degree $\dagger$ & 0.29 & 0.45 & 0 & 0 & 1 & 730 \\
High school diploma $\dagger$ & 0.23 & 0.42 & 0 & 0 & 1 & 730 \\
\hline
\end{tabular}

Panel B - Men

\begin{tabular}{lcccccc}
\hline & Mean & St.Dev. & Median & Min & Max & N \\
\hline Age (in years) & 39.0 & 9.6 & 38 & 23 & 64 & 240 \\
Experience (in years) & 6.1 & 6.0 & 5 & 0 & 30 & 187 \\
Test score & 58.2 & 11.7 & 59 & 16 & 99 & 224 \\
Passed 2nd level exam $\dagger$ & 0.27 & 0.45 & 0 & 0 & 1 & 242 \\
University degree $\dagger$ & 0.45 & 0.50 & 0 & 0 & 1 & 236 \\
College degree $\dagger$ & 0.31 & 0.46 & 0 & 0 & 1 & 236 \\
High school diploma $\dagger$ & 0.14 & 0.34 & 0 & 0 & 1 & 236 \\
\hline
\end{tabular}

Panel C - Women

\begin{tabular}{lcccccc}
\hline & Mean & St.Dev. & Median & Min & Max & N \\
\hline Age (in years) & 45.8 & 8.0 & 47 & 24 & 60 & 500 \\
Experience (in years) & 6.4 & 5.4 & 5 & 0 & 33 & 404 \\
Test score & 54.5 & 11.1 & 55 & 20 & 91 & 470 \\
Passed 2nd level exam $\dagger$ & 0.16 & 0.37 & 0 & 0 & 1 & 500 \\
University degree $\dagger$ & 0.16 & 0.36 & 0 & 0 & 1 & 494 \\
College degree $\dagger$ & 0.28 & 0.45 & 0 & 0 & 1 & 494 \\
High school diploma $\dagger$ & 0.28 & 0.45 & 0 & 0 & 1 & 494 \\
\hline
\end{tabular}




\section{Table 2: Sophistication proxy cross-correlations}

The Spearman rank correlations between the five potential sophistication proxy variables. $\dagger$ denotes dummy variables. The correlation coefficients shown in bold face are different from zero at the $5 \%$ significance level. The p-value is shown in the parenthesis.

\begin{tabular}{|c|c|c|c|c|}
\hline & 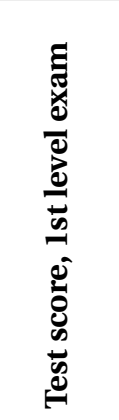 & 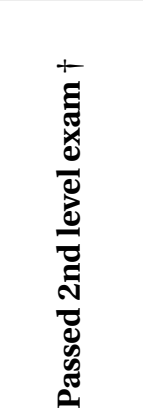 & 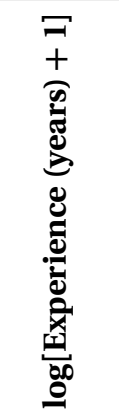 & $\begin{array}{l}+\infty \\
\stackrel{0}{0} \\
\overline{0} \\
\dot{0}\end{array}$ \\
\hline Passed 2nd level exam $\dagger$ & $\begin{array}{c}\mathbf{0 . 0 9} \\
(0.048)\end{array}$ & & & \\
\hline $\log [$ Experience $($ years $)+1]$ & $\begin{array}{c}0.08 \\
(0.075)\end{array}$ & $\begin{array}{c}0.08 \\
(0.067)\end{array}$ & & \\
\hline College $\dagger$ & $\begin{array}{c}\mathbf{0 . 1 4} \\
(0.002)\end{array}$ & $\begin{array}{c}\mathbf{0 . 1 5} \\
(<0.001)\end{array}$ & $\begin{array}{c}-0.09 \\
(0.062)\end{array}$ & \\
\hline Gender, female $\dagger$ & $\begin{array}{c}\mathbf{- 0 . 1 0} \\
(0.021)\end{array}$ & $\begin{array}{c}\mathbf{- 0 . 1 7} \\
(<0.001)\end{array}$ & $\begin{array}{c}0.07 \\
(0.152)\end{array}$ & $\begin{array}{c}\mathbf{- 0 . 2 4} \\
(<0.001)\end{array}$ \\
\hline
\end{tabular}




\section{Table 3: Sophistication, forecast ability, and information sources}

The effect of sophisication index on self-perceived forecast ability and information sources used as a basis for forming stock return expectations. Frequency denotes the fraction of respondents in the logit model having the specific forecast dummy variable equal to one. Univariate columns show the estimated sophistication effect coefficients and robust z-statistics for a model that includes only sophistication as an explanatory variable. Full model columns show the coefficients and z-statistics for models which also include log experience, log age, and employer fixed effects as control variables. Panel A shows the sophistication effect estimates for two logit models explaining being a not worse forecaster and being a better forecaster, and also for an ordered logit model explaining the probability of being a forecaster of the three possible types: worse, average, or better than average. Panel B shows the estimated marginal sophistication effects of logit models explaining the likelihood of using various sources of information as a basis for stock return expectations. In panel $\mathrm{B}$, the full model controls also include forecast ability. ${ }^{* * *}$ and ${ }^{* *}$ denote statistical significance at the $1 \%$ and $5 \%$ levels.

Panel A: Sophistication and forecast ability

\begin{tabular}{lccccccc}
\hline & \multirow{2}{*}{$\begin{array}{c}\text { Frequency } \\
\text { (in \%) }\end{array}$} & & \multicolumn{2}{c}{ univariate } & & \multicolumn{2}{c}{ full model } \\
& & & coeff. & z-stat & & coeff. & z-stat \\
\hline Not worse forecaster & 91.5 & & $0.40^{* * *}$ & 3.3 & & $0.42^{* *}$ & 2.1 \\
Better forecaster & 8.9 & & $0.44^{* * *}$ & 2.9 & & 0.23 & 1.2 \\
Ordered logit & - & & $0.41^{* * *}$ & 4.2 & & $0.30^{* *}$ & 2.2 \\
\hline Control variables included & \multicolumn{2}{c}{ No } & & \multicolumn{2}{c}{ Yes } \\
\hline
\end{tabular}

Panel B: Sophistication and information sources

\begin{tabular}{|c|c|c|c|c|c|}
\hline & \multirow{2}{*}{$\begin{array}{l}\text { Frequency } \\
\quad \text { (in \%) }\end{array}$} & \multicolumn{2}{|c|}{ univariate } & \multicolumn{2}{|c|}{ full model } \\
\hline & & coeff. & z-stat & coeff. & z-stat \\
\hline employer material, strategy reviews etc. & 70.7 & 0.08 & 1.0 & 0.02 & 0.2 \\
\hline financial media & 44.6 & 0.01 & 0.1 & 0.03 & 0.3 \\
\hline interest rates & 38.2 & $0.21^{* *}$ & 2.6 & $0.25^{* *}$ & 2.4 \\
\hline discussions with collegues & 28.6 & -0.01 & -0.1 & -0.04 & -0.4 \\
\hline economic statistics and ratios & 26.3 & $0.22^{* *}$ & 2.2 & $0.23^{* *}$ & 2.0 \\
\hline outside strategy reviews & 23.7 & $0.25^{* *}$ & 2.4 & 0.15 & 1.2 \\
\hline historical returns & 19.4 & 0.12 & 1.2 & 0.08 & 0.7 \\
\hline other & 3.4 & -0.18 & -0.7 & -0.18 & -0.6 \\
\hline Control variables included & & \multicolumn{2}{|l|}{ No } & \multicolumn{2}{|l|}{ Yes } \\
\hline
\end{tabular}




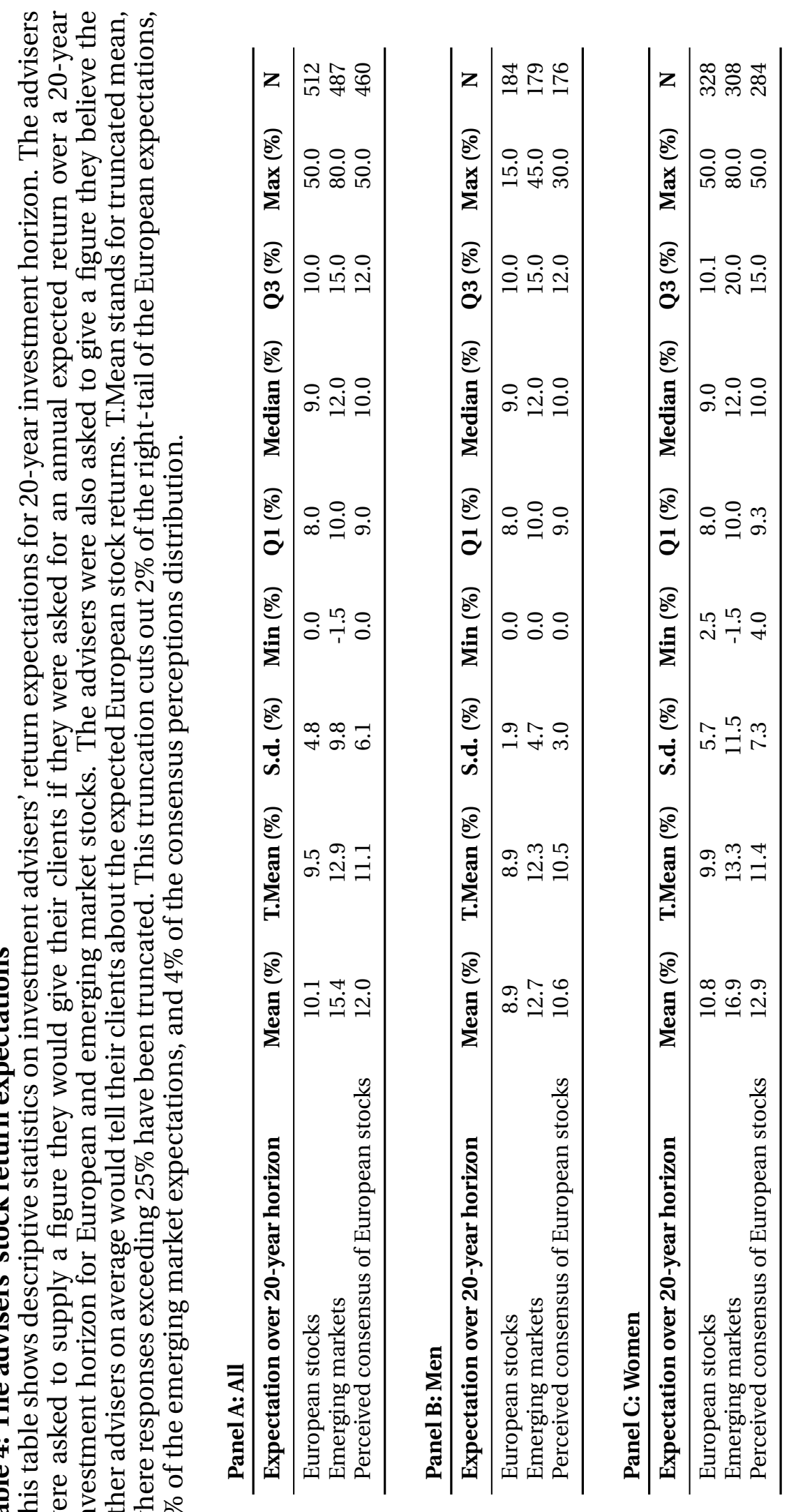




\section{Table 5: The determinants of advisers' stock return expectations}

Investment advisers' 20-year European stock return expectations regressed on sophistication composite index, log experience, log age, and self-perceived stock returns forecast ability. The sophistication index is a proxy for unobserved sophistication derived from factor analysis using test score, second level examination dummy, gender, and college dummy. Better (Worse) than average dummy variables equal 1 if the subject self-reports being better (worse) than the average adviser in forecasting future returns. The t-statistics based on heteroskedasticity robust standard errors are shown in parenthesis. The italicized figures in the gray columns depict percentages of adjusted $\mathrm{R}^{2}$ decompositions calculated using the Shapley decomposition method of Shorrocks (1999). ${ }^{* * *}, * *$, and * denote statistical significance at $1 \%, 5 \%$, and $10 \%$ levels respectively.

\begin{tabular}{|c|c|c|c|c|c|c|c|c|}
\hline & $(\mathbf{1})$ & & $(2)$ & & (3) & & $(4)$ & \\
\hline Constant & $\begin{array}{l}10.2^{* * *} \\
(25.07)\end{array}$ & & $\begin{array}{l}10.2^{* * *} \\
(15.19)\end{array}$ & & $\begin{array}{r}4.7 \\
(1.16)\end{array}$ & & $\begin{array}{r}4.7 \\
(1.14)\end{array}$ & \\
\hline Sophistication composite index & $\begin{array}{l}-1.2^{* * *} \\
(-5.26)\end{array}$ & 76.9 & $\begin{array}{l}-1.2^{* * *} \\
(-5.15)\end{array}$ & 75.4 & $\begin{array}{l}-1.1^{* * *} \\
(-4.24)\end{array}$ & 62.5 & $\begin{array}{l}-1.1^{* * *} \\
(-4.36)\end{array}$ & 61.4 \\
\hline $\log [$ experience (years) +1$]$ & & & $\begin{array}{r}-0.1 \\
(-0.36)\end{array}$ & 0.6 & $\begin{array}{r}-0.3 \\
(-0.74)\end{array}$ & 3.4 & $\begin{array}{r}-0.5 \\
(-1.09)\end{array}$ & 3.1 \\
\hline $\log [$ age (years)] & & & & & $\begin{array}{r}1.6 \\
(1.36)\end{array}$ & 9.5 & $\begin{array}{r}1.7 \\
(1.41)\end{array}$ & 9.2 \\
\hline Better than average forecaster & & & & & & & $\begin{array}{r}0.2 \\
(0.44)\end{array}$ & -2.2 \\
\hline Worse than average forecaster & & & & & & & $\begin{array}{l}-1.7^{* *} \\
(-2.48) \\
\end{array}$ & 4.0 \\
\hline Employer fixed-effects & Yes & 23.1 & Yes & 24.0 & Yes & 24.6 & Yes & 24.5 \\
\hline Adjusted $\mathrm{R}^{2}$ & 0.076 & 100 & 0.078 & 100 & 0.079 & 100 & 0.083 & 100 \\
\hline $\mathbf{N}$ & \multicolumn{2}{|l|}{481} & \multicolumn{2}{|l|}{435} & \multicolumn{2}{|l|}{434} & \multicolumn{2}{|c|}{434} \\
\hline
\end{tabular}


Table 6: The determinants of advisers' emerging market stock return expectations Investment advisers' 20-year emerging market stock return expectations regressed on sophistication composite index, log experience, log age, and self-perceived stock returns forecast ability. The sophistication index is a proxy for unobserved sophistication derived from factor analysis using test score, second level examination dummy, college dummy, and gender dummy. Better (Worse) than average dummy variables equal 1 if the subject self-reports being better (worse) than the average adviser in forecasting future returns. The t-statistics based on heteroskedasticity robust standard errors are shown in parenthesis. The italicized figures in the gray columns depict percentages of adjusted $\mathrm{R}^{2}$ decompositions calculated using the Shapley decomposition method of Shorrocks (1999). ***, **, and * denote statistical significance at $1 \%$, $5 \%$, and $10 \%$ levels respectively.

\begin{tabular}{|c|c|c|c|c|c|c|c|c|}
\hline \multirow[b]{2}{*}{ Constant } & \multicolumn{2}{|l|}{$(1)$} & \multicolumn{2}{|l|}{$(2)$} & \multicolumn{2}{|l|}{ (3) } & \multicolumn{2}{|c|}{$(4)$} \\
\hline & $\begin{array}{l}15.3^{* * *} \\
(13.68)\end{array}$ & & $\begin{array}{l}16.2^{* * *} \\
(10.69)\end{array}$ & & $\begin{array}{r}-4.9 \\
(-0.58)\end{array}$ & & $\begin{array}{r}-5.2 \\
(-0.60)\end{array}$ & \\
\hline Sophistication composite index & $\begin{array}{l}-2.9^{* * *} \\
(-6.99)\end{array}$ & 78.5 & $\begin{array}{l}-2.8^{* * *} \\
(-6.77)\end{array}$ & 81.1 & $\begin{array}{l}-2.3^{* * *} \\
(-5.28)\end{array}$ & 58.3 & $\begin{array}{l}-2.3^{* * *} \\
(-5.29)\end{array}$ & 59.7 \\
\hline $\log [$ experience (years) +1$]$ & & & $\begin{array}{r}-0.5 \\
(-0.76)\end{array}$ & -0.9 & $\begin{array}{r}-1.2 \\
(-1.44)\end{array}$ & 3.1 & $\begin{array}{c}-1.3^{*} \\
(-1.67)\end{array}$ & 2.7 \\
\hline log[age (years)] & & & & & $\begin{array}{l}6.0^{* *} \\
(2.44)\end{array}$ & 19.0 & $\begin{array}{l}6.1^{* *} \\
(2.47)\end{array}$ & 19.4 \\
\hline Better than average forecaster & & & & & & & $\begin{array}{r}0.5 \\
(0.50)\end{array}$ & -1.2 \\
\hline Worse than average forecaster & & & & & & & $\begin{array}{r}-0.8 \\
(-0.37) \\
\end{array}$ & -0.8 \\
\hline Employer fixed-effects & Yes & 21.5 & Yes & 19.8 & Yes & 19.6 & Yes & 20.2 \\
\hline Adjusted $\mathrm{R}^{2}$ & 0.112 & 100 & 0.110 & 100 & 0.122 & 100 & 0.119 & 100 \\
\hline $\mathbf{N}$ & 456 & & 416 & & 415 & & 415 & \\
\hline
\end{tabular}




\section{Table 7: Additional results and robustness checks}

This table collates results from additional analysis. Columns (1), (2), and (3) show the results of regression models regressing the expected 20-year returns pooling the European and emerging market return expectations together (1), controlling for random (2), and controlling for fixed individual effects (3). Columns (4) and (5) show the estimates from a probit model explaining the response to the return expectation question separately for European and emerging market expectations. Column (6) shows the determinants of expected 10-year emerging market returns from a series of later surveys of financial advisers between years 2009 and 2012. Sophistication composite index is a proxy for unobserved sophistication derived from factor analysis using test score, second level examination dummy, college dummy, and gender dummy as inputs. The sophistication index (new) is a proxy for sophistication derived from the gender and logic test variables included in the 2009-2012 expectations surveys. Emerging mkt dummy equals 1 for emerging market expetecte returns, 0 for european returns. The tstatistics based on clustered standard errors (z-statistics based on robust standard errors for the probit models) are shown in parenthesis. The $\mathrm{R}^{2}$ statistic for models (1) and (6) is the ordinary OLS measure, and for models (2) and (3) the overall $\mathrm{R}^{2}$ measure. Models (4) and (5) report McFadden (1974) pseudo- $\mathrm{R}^{2}$ s. ${ }^{* * *},{ }^{* *}$, and ${ }^{*}$ denote statistical significance at $1 \%, 5 \%$, and $10 \%$ levels respectively.

\begin{tabular}{|c|c|c|c|c|c|c|}
\hline & \multirow{2}{*}{\multicolumn{3}{|c|}{$\begin{array}{c}\text { Expected 20-year return } \\
\text { (Pooled Euro-emerging mkt) }\end{array}$}} & \multicolumn{2}{|c|}{$\begin{array}{l}\text { Marginal probability of } \\
\text { response in percentages }\end{array}$} & \multirow{3}{*}{$\begin{array}{c}\text { Exp. return, } \\
2009-12 \\
\text { surveys }\end{array}$} \\
\hline & & & & \multirow{2}{*}{$\begin{array}{c}\text { European } \\
(4)\end{array}$} & \multirow{2}{*}{$\begin{array}{c}\text { Emerging } \\
(5)\end{array}$} & \\
\hline & (1) & (2) & (3) & & & \\
\hline Constant & $\begin{array}{r}-2.6 \\
(-0.46)\end{array}$ & $\begin{array}{r}-2.5 \\
(-0.46)\end{array}$ & $\begin{array}{r}10.2 \\
(56.04)\end{array}$ & $\begin{array}{r}0.8 \\
(0.68)\end{array}$ & $\begin{array}{r}1.0 \\
(0.90)\end{array}$ & $\begin{array}{r}12.0 \\
(18.52)\end{array}$ \\
\hline Sophistication composite index & $\begin{array}{l}-0.9^{* * *} \\
(-3.18)\end{array}$ & $\begin{array}{l}-0.9^{* * *} \\
(-3.18)\end{array}$ & & $\begin{array}{l}0.2^{* * *} \\
(3.19)\end{array}$ & $\begin{array}{l}0.2^{* * *} \\
(3.12)\end{array}$ & \\
\hline Sophistication index (new) & & & & & & $\begin{array}{l}-0.9^{* * *} \\
(-2.74)\end{array}$ \\
\hline Emerging mkt dummy & $\begin{array}{l}5.3^{* * *} \\
(13.04)\end{array}$ & $\begin{array}{l}5.4^{* * *} \\
(13.58)\end{array}$ & $\begin{array}{l}5.5^{* * *} \\
(13.99)\end{array}$ & & & \\
\hline $\begin{array}{l}\text { Sophistication index } \\
\times \text { Emerging mkt dummy }\end{array}$ & $\begin{array}{l}-1.6^{* * *} \\
(-4.53)\end{array}$ & $\begin{array}{l}-1.7^{* * *} \\
(-4.77)\end{array}$ & $\begin{array}{l}-1.8^{* * *} \\
(-4.98)\end{array}$ & & & \\
\hline $\log [$ experience (years) +1$]$ & $\begin{array}{r}-0.7 \\
(-1.37)\end{array}$ & $\begin{array}{r}-0.7 \\
(-1.27)\end{array}$ & & $\begin{array}{l}0.4^{* * *} \\
(2.92)\end{array}$ & $\begin{array}{l}0.3^{* * *} \\
(3.19)\end{array}$ & $\begin{array}{r}0.2 \\
(0.60)\end{array}$ \\
\hline log[age (years)] & $\begin{array}{l}3.7^{* *} \\
(2.30)\end{array}$ & $\begin{array}{l}3.7^{* *} \\
(2.29)\end{array}$ & & $\begin{array}{r}-0.1 \\
(-0.36)\end{array}$ & $\begin{array}{r}-0.2 \\
(-0.71)\end{array}$ & \\
\hline Employer fixed-effects & Yes & Yes & N/A & Yes & Yes & No \\
\hline Time dummies & - & - & - & - & - & Yes \\
\hline Individual effects & Pooled & Random & Fixed & - & - & - \\
\hline $\mathbf{R}^{2}$ & 0.212 & 0.212 & 0.158 & 0.057 & 0.042 & 0.114 \\
\hline $\mathbf{N}$ & 849 & 849 & 849 & 552 & 552 & 239 \\
\hline
\end{tabular}


Table 8: The determinants of advisers' return expectations with a separate gender effect Investment advisers' 20-year European and emerging market stock return expectations regressed on sophistication composite index, log experience, log age, gender, and selfperceived stock returns forecast ability. The sophistication index used in this table is created without gender information. Gender dummy equals 1 if the subject is female, 0 if male. Better (Worse) than average dummy variables equal 1 if the subject self-reports being better (worse) than the average adviser in forecasting future returns. The t-statistics based on heteroskedasticity robust standard errors are shown in parenthesis. The italicized figures in the gray columns depict percentages of adjusted $\mathrm{R}^{2}$ decompositions calculated using the Shapley decomposition method of Shorrocks (1999). ***, **, and * denote statistical significance at 1\%, $5 \%$, and $10 \%$ levels respectively.

\begin{tabular}{|c|c|c|c|c|c|c|c|c|}
\hline & \multicolumn{4}{|c|}{ European } & \multicolumn{4}{|c|}{ Emerging market } \\
\hline & (1) & & $(2)$ & & (1) & & (2) & \\
\hline Constant & $\begin{aligned} & 9.9 * * * \\
&(14.75)\end{aligned}$ & & $\begin{array}{r}4.2 \\
(1.03)\end{array}$ & & $15.4^{* * *}$ & & $\begin{array}{r}-6.5 \\
-0.56)\end{array}$ & \\
\hline Sophistication index (excl. gender) & $\begin{array}{l}-1.0^{* * *} \\
(-4.36)\end{array}$ & 66.9 & $\begin{array}{l}-0.7^{* * *} \\
(-3.17)\end{array}$ & 34.0 & $\begin{array}{l}-2.4^{* * *} \\
(-6.11)\end{array}$ & 76.1 & $\begin{array}{l}-1.7^{* * *} \\
(-4.15)\end{array}$ & 40.5 \\
\hline $\log [$ experience (years) +1$]$ & $\begin{array}{r}-0.1 \\
(-0.21)\end{array}$ & 0.7 & $\begin{array}{r}-0.5 \\
(-1.16)\end{array}$ & 3.2 & $\begin{array}{r}-0.4 \\
(-0.55)\end{array}$ & -1.0 & $\begin{array}{l}-1.3^{*} \\
(-1.69)\end{array}$ & 2.5 \\
\hline log[age (years)] & & & $\begin{array}{r}1.6 \\
(1.32)\end{array}$ & 7.3 & & & $\begin{array}{l}6.0^{* *} \\
(2.43)\end{array}$ & 17.7 \\
\hline Gender, female & & & $\begin{array}{l}1.6^{* * *} \\
(3.91)\end{array}$ & 28.8 & & & $\begin{array}{l}2.6^{* * *} \\
(3.11)\end{array}$ & 20.9 \\
\hline Better than average forecaster & & & $\begin{array}{r}0.4 \\
(0.72)\end{array}$ & -2.1 & & & $\begin{array}{r}0.6 \\
(0.62)\end{array}$ & -1.2 \\
\hline Worse than average forecaster & & & $\begin{array}{c}-1.8^{* *} \\
(-2.56) \\
\end{array}$ & 4.5 & & & $\begin{array}{r}-0.9 \\
(-0.41) \\
\end{array}$ & -0.9 \\
\hline Employer fixed-effects & Yes & 32.4 & Yes & 24.4 & Yes & 24.9 & Yes & 20.6 \\
\hline Adjusted $\mathbf{R}^{2}$ & 0.059 & 100 & 0.083 & 100 & 0.087 & 100 & 0.117 & 100 \\
\hline $\mathbf{N}$ & 435 & & 43 & & 416 & & 415 & \\
\hline
\end{tabular}


Figure 1: Information sources for return expectations

The frequency of mentioning a source as a key information source for basing stock return expectations.

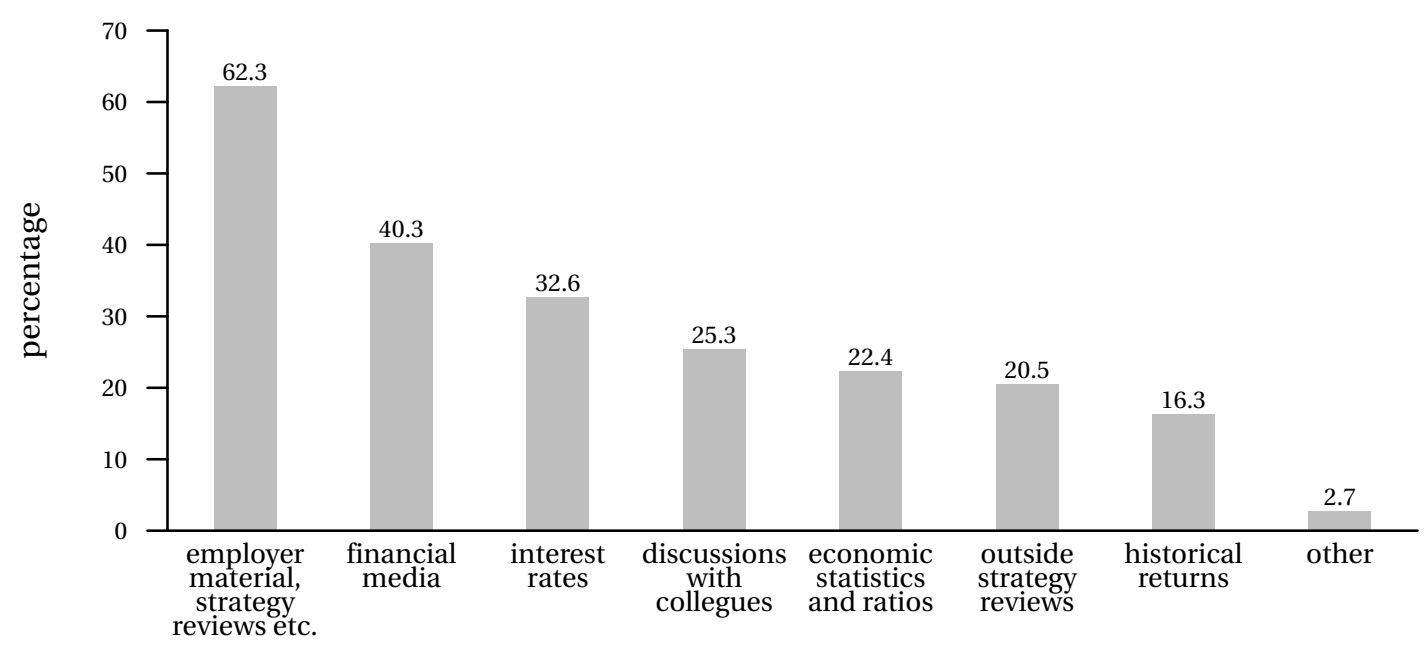




\section{Figure 2: Distribution of the expected returns}

Figure a) shows the kernel density estimate of 20-year European return distributions (Epanechnikov kernel, bandwidth $=0.7 \%$ ), and figure b) shows the density estimate for 20year emerging market return distributions (Epanechnikov kernel, bandwidth $=1.0 \%$ ). The model residual curves display the distribution of linear model residuals centered at the mean of the raw returns. This linear model controls for a rich set of covariates, including employer fixed effects. The raw return distribution using the sample included in the regression model is shown in gray for comparison. The employer information subsample curves display the distribution of the same linear model residuals for a subsample where all respondents report employer information as a primary source for basing return expectations.

a) European stocks, 20-year

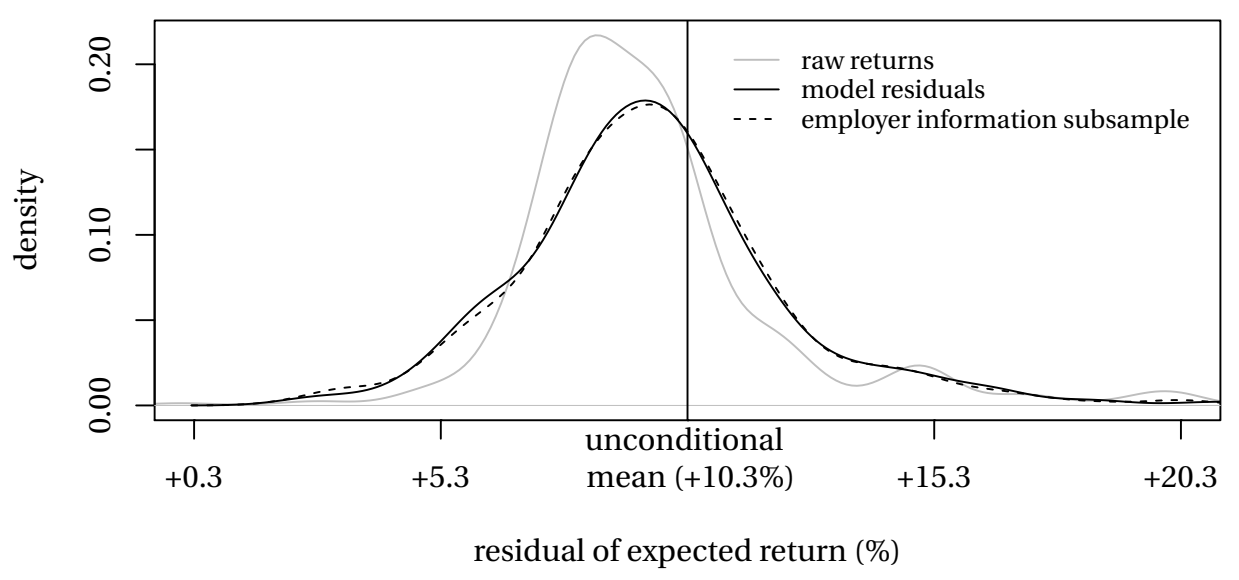

b) Emerging market stocks, 20-year

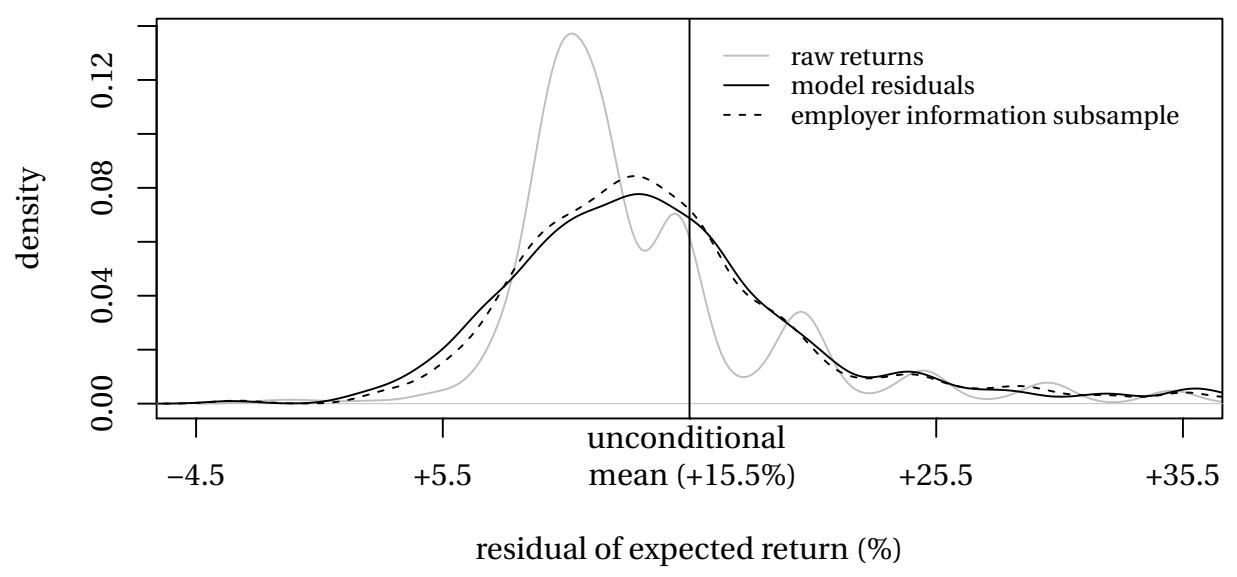




\section{Figure 3: Expected returns by sophistication quintiles}

Average expected European and emerging market 20 -year returns by sophistication quintiles. The quintiles are formed using a composite sophistication index derived from factor analysis using test score, second level examination, gender, and college dummy. The triangles connected by dashed lines show the emerging market expected returns by sophistication quintiles. The crosses connected by solid lines show the European market expected returns.

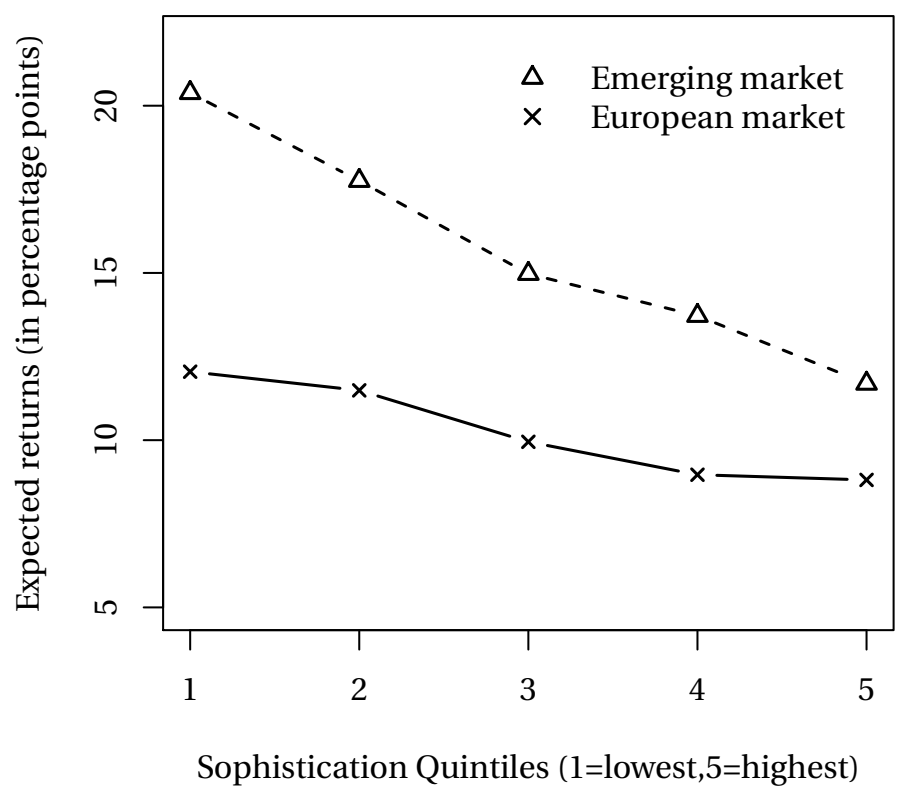


Figure 4: Gender effect on expected returns by sophistication terciles

The levels of the estimated gender effects (coefficient for a dummy taking the value of one for women, zero for men) from regression models corresponding to those reported as model (2) in Table 8. Grey bar color denotes statistically significant coefficient at the $5 \%$ level. White bar denotes statistically insignificant coefficients. The terciles are formed using a version of the composite sophistication index that excludes gender.

a) European stocks

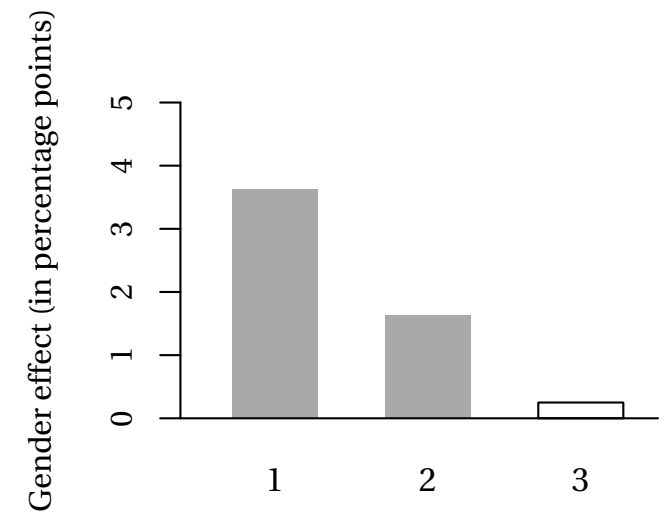

Sophistication Terciles (1=lowest, $3=$ highest) b) Emerging market stocks

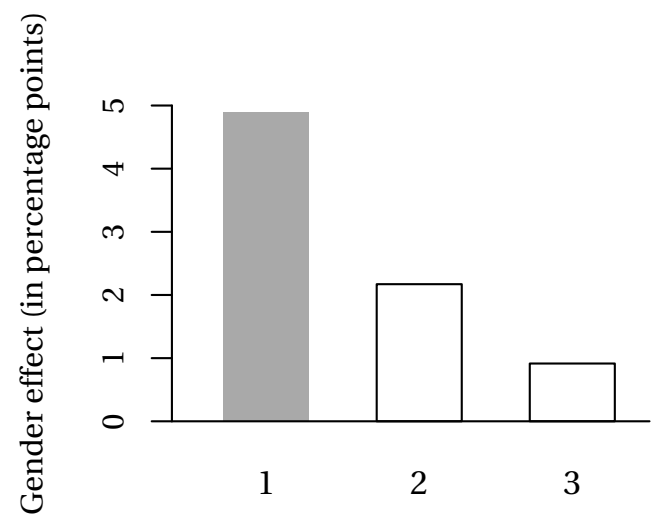

Sophistication Terciles (1=lowest, $3=$ highest) 


\section{Recent Issues}

No. 2 Markku Kaustia - Samuli Knüpfer - Sami Torstila

No. 1 Dimitris Georgarakos - Michalis Haliassos - Giacomo Pasini
Stock Ownership and Political Behavior: Evidence from Demutualization Household Debt and Social Interaction 